\title{
TEM and PEELS Study of Mn Diffusion in an MRAM Structure
}

\author{
S. X. Wang, M. M. Kowalewski
}

Micron Technology, Inc., Boise, ID 83707, USA

The Mn diffusion phenomenon in a megnetoresistive random access memory (MRAM) multilayer stack is studied using a transmission electron microscope (TEM) and a parallel electron energyloss spectrometer (PEELS). Thermally activated $\mathrm{Mn}$ diffusion to the interface of the $\mathrm{Al}_{2} \mathrm{O}_{3}$ tunneling barrier and ferromagnetic NiFe might be responsible for the drop of tunneling magnetoresistance (TMR) in MRAM bits.

The TEM sample was prepared by using a focused ion beam (FIB) technique. TEM and PEELS analyses were performed on JEOL2010F with a Gatan GIF-PEELS system. FIG. 1A shows a Zcontrast, high-angle, annular dark-field STEM image of the multilayer

(Ta/MnIr/NiFe/ $\mathrm{Al}_{2} \mathrm{O}_{3} / \mathrm{NiFe} / \mathrm{Ta}$ ). PEELS (FIG. 1B) data was collected with the electron beam scanning across the structure, along the line indicated in FIG. 1A. From the Mn profile (FIG. 1B), we observed the diffusion of $\mathrm{Mn}$ through the $\mathrm{NiFe}$ layer into the $\mathrm{Al}_{2} \mathrm{O}_{3}$ layer. In transition metals, $\mathrm{L}_{3}$ and $\mathrm{L}_{2}$ white lines $\left(2 \mathrm{p}^{3 / 2} \rightarrow 3 \mathrm{~d}^{3 / 2} 3 \mathrm{~d}^{5 / 2}, 2 \mathrm{p}^{1 / 2} \rightarrow 3 \mathrm{~d}^{3 / 2}\right)$ are observed in the energy-loss spectra [1]. The comparison of the $\mathrm{Mn} \mathrm{L}_{2,3}$ edges from the MnIr layer and $\mathrm{NiFe} / \mathrm{Al}_{2} \mathrm{O}_{3}$ interface (FIG. 2A) shows a significant difference in the fine structures. The intensity ratio of $\mathrm{L}_{3}: \mathrm{L}_{2}$ is much larger for diffused $\mathrm{Mn}$ in $\mathrm{Al}_{2} \mathrm{O}_{3}$. It has been shown that the relative intensities of $\mathrm{L}_{3}$ and $\mathrm{L}_{2}$ of $\mathrm{Mn}$ are highly sensitive to the $3 \mathrm{~d}$ occupancy and thus the valence state [1-3]. The spectra, as shown in FIG. 2A, were processed using the Fourier ratio method for removing the plural scattering effect [4]. The intensity ratio of white lines $\mathrm{I}\left(\mathrm{L}_{3}\right) / \mathrm{I}\left(\mathrm{L}_{2}\right)$ is calculated from the spectra using the double-step background fitting procedure with the step at the peak $[1,2]$. FIG. $2 \mathrm{~B}$ plots $\mathrm{I}\left(\mathrm{L}_{3}\right) / \mathrm{I}\left(\mathrm{L}_{2}\right)$ vs. the $\mathrm{Mn}$ valence state for the reference data (ref. [2]) and for the data from the current study. From the correlation of our current data $\left(\mathrm{I}\left(\mathrm{L}_{3}\right) / \mathrm{I}\left(\mathrm{L}_{2}\right) \cong 3.3\right.$ for $\mathrm{Mn}$ in $\left.\mathrm{Al}_{2} \mathrm{O}_{3}\right)$ to the reference data, we conclude that the mean valence state of $\mathrm{Mn}$ in $\mathrm{Al}_{2} \mathrm{O}_{3}$ is $\sim+2.2$. Thus, $\mathrm{Mn}$ diffused into the $\mathrm{Al}_{2} \mathrm{O}_{3}$ layer and accumulated there in an oxidized state.

The temperature effect on the Mn diffusion was studied. The PEELS analysis was repeated on samples with different thermal treatments (no annealing, annealed at $220^{\circ} \mathrm{C}$, annealed at $250^{\circ} \mathrm{C}$ ). It was observed that the $\mathrm{Mn}$ amount in the $\mathrm{Al}_{2} \mathrm{O}_{3}$ increases with annealing temperatures. The relative $\mathrm{Mn}: \mathrm{O}$ ratio at the $\mathrm{NiFe} / \mathrm{Al}_{2} \mathrm{O}_{3}$ interface was calculated from the elemental profiles. The $\mathrm{Mn}: \mathrm{O}$ ratio is qualitative at this stage, mainly because the $\mathrm{NiFe} / \mathrm{Al}_{2} \mathrm{O}_{3}$ interface roughness and sample tilt affect the measured $\mathrm{Mn}: \mathrm{O}$ ratio. To minimize this variation, the $\mathrm{Mn}: \mathrm{O}$ ratio was calculated by integrating the elemental profile over a $3 \mathrm{~nm}$ range around the $\mathrm{Mn}$ peak location at the $\mathrm{NiFe} / \mathrm{Al}_{2} \mathrm{O}_{3}$ interface. The measured $\mathrm{Mn}: \mathrm{O}$ ratio at the interface, as a function of annealing temperatures, is shown in FIG. 3, where there is a significant increase of Mn diffusion with a higher annealing temperature. The existence of diffused $\mathrm{Mn}$ in the nonannealed sample indicates that the $\mathrm{Mn}$ diffusion occurred during the MRAM production process.

\section{References}

[1] D. H. Pearson et al., Phys. Rev. B 47 (1993) 8471.

[2] Z. L. Wang et al., Appl. Phys. Lett. 70 (1997) 3362.

[3] J. L. Mansot et al., Microsc. Microanal. Microstruct. 5 (1994) 79.

[4] R. F. Egerton, Electron Energy-Loss Spectroscopy in the Transmission Electron Microscopy, 2nd ed., Plenum, New York, 1996. 


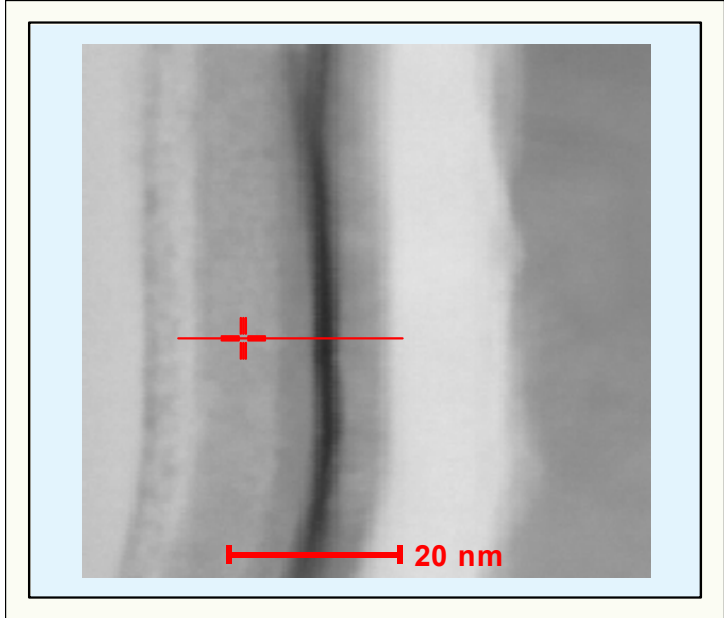

(A)

FIG. 1. (A) STEM image of the magnetic stack. (B) Elemental profiles obtained using PEELS signal as the electron beam scanned along the line in (A) from left to right.

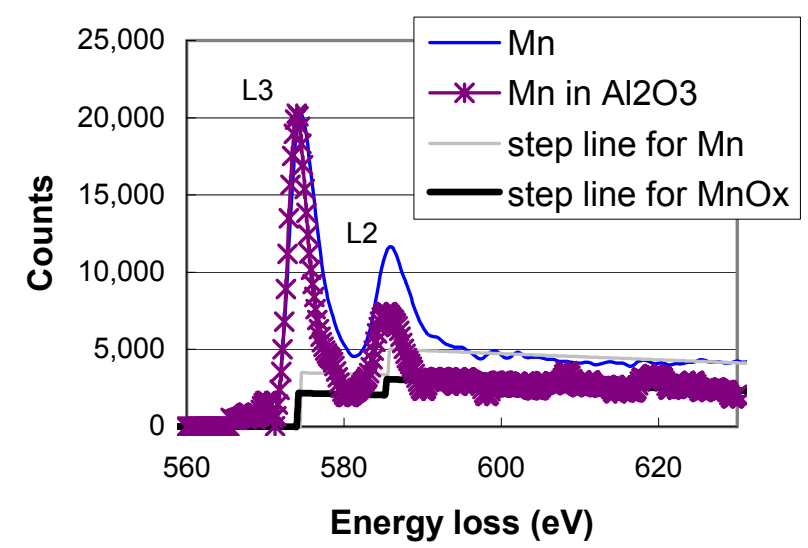

(A)

(B)

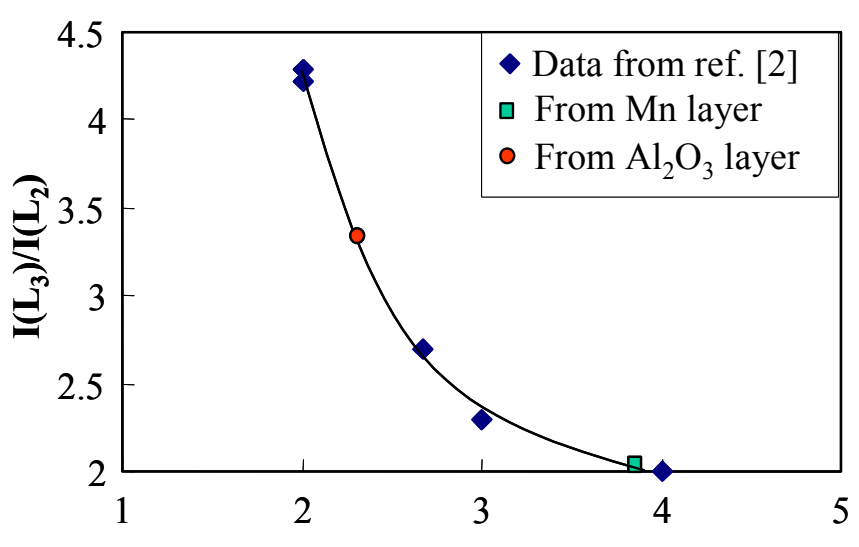

Mn Valence

FIG. 2. (A) Comparison of Manganese $\mathrm{L}_{2,3}$ edge spectra from $\mathrm{Mn}$ layer and from $\mathrm{Al}_{2} \mathrm{O}_{3}$ layer. (B) A plot of white line intensity ratio $\mathrm{I}\left(\mathrm{L}_{3}\right) / \mathrm{I}\left(\mathrm{L}_{3}\right)$ versus the valence state of $\mathrm{Mn}$.

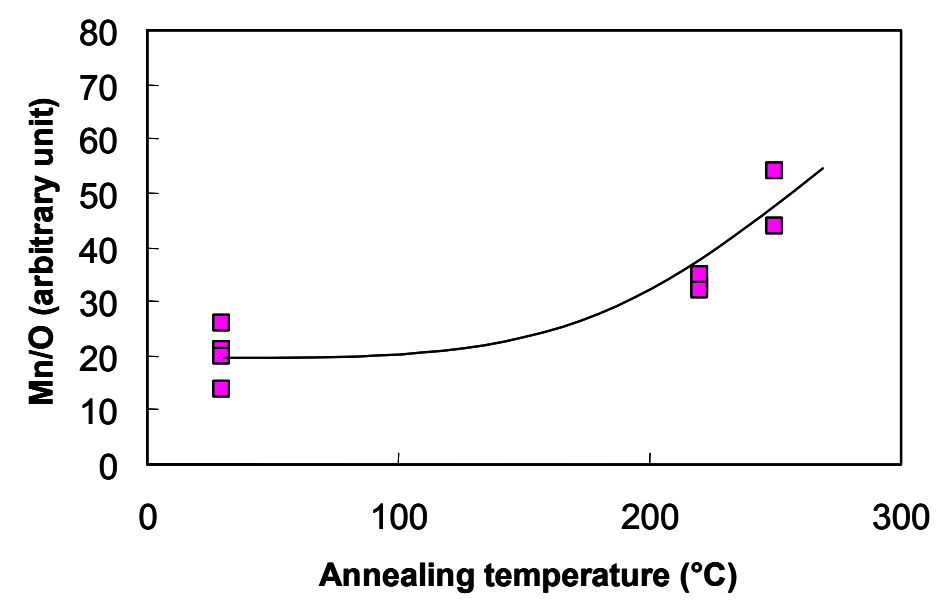

FIG. 3. $\mathrm{Mn}$ :O ratio at the $\mathrm{NiFe} / \mathrm{Al}_{2} \mathrm{O}_{3}$ interface as a function of annealing temperature. 